\section{... and in Neuroscience}

\section{R. Victoria Stirling}

Developmental Neuroscience. Editors-inchief A. Vernadakis and E. Giacobini. 6/yr. (Karger, Basel.) SwFr.130.20, DM $162.40, \$ 74.20$ (personal); SwFr.186, DM $232, \$ 106$ (institutional).

IN THE absence of any editorial statement in the issues available to me, the objectives of Developmental Neuroscience (DN), a new general journal of developmental neurobiology, must be judged from its contents. Unfortunately, it is not clear from a survey of the papers in Vol. 3 (1980) what is the direction or editorial policy of this newcomer.

Most papers are well-written and coherent, many of them confirming earlier work rather than breaking new ground. Only three are concerned with my own research interest, the development of patterned neuronal connections; most of the rest are biochemical in nature, discussing the regulation of brain function and metabolism by hormones, undernutrition and ageing. At the other extreme are a few purely morphological papers, describing maturation of synaptic endings in the vestibular nucleus of the chicken and the use of immunofluorescent methods in the study of neurofilaments in early development.

\section{Developmental Neuroscience}

The papers are almost all 10 pages long (including the well-reproduced illustrations), doubtless the result of a $\$ 105$ excess page charge. Exceptions appear to be made, however; a very full description of the structure of thyroxine-induced infrapyramidal mossy fibres in rat is 18 pages long, with an abstract of 24 lines (the stipulated length is 10 lines), perhaps because both authors are on the editorial board! Speed of publication appears to be much the same as other journals in this area, but no dates of acceptance appear with the papers.

While the birth of specialized journals is justified by the recent mushrooming of developmental neurobiological research, there does seem to be an urgent need for yet another general journal. The combination of the last three parts of Vol. 3 in one issue may indicate that $\mathrm{DN}$ has not yet found its niche.

R. Victoria Stirling is at the National Institute for Medicàl Research, Mill Hill, London.

\title{
Trait Psychology Fights Back
}

\section{Chris Brand}

Personality and Individual Differences. Editor-in-chief H.J. Eysenck. 4/yr. (Pergamon.) \$65.

WITH the break-up of the British Journal of Social and Clinical Psychology into its named components, Hans Eysenck has filled the gap that resulted for differential psychology in general and for the London School in particular. So far, after some six high-quality issues of scholarly, empirical reports in Personality and Individual Differences (PID), the evidence is that, despite a decade of environmentalism and situationism in psychology, trait approaches to human differences are still alive and kicking.

Undoubtedly the outstanding report to have been carried is that of D.E. and A.E. Hendrickson, "The Biological Basis of Individual Differences in Intelligence"; but this is complemented by other physiological enquiries - particularly concerning Eysenck's third dimension of personality, psychoticism, and related traits of impulsiveness and sensation-seeking. Naturally, many of the papers are addressed to whether or not Eysenck has got matters right: but, across large areas of differential psychology, this is by now a helpful catch-all question that researchers can reasonably be expected to consider; and contributors to PID are evidently not required to agree about the answer. Above all, there is a healthy proportion of distinguished contributors; and the journal is catholic in the psychometric measures reported, in the subjects studied and in the countries from which the reports originate.

In general, the sound empiricism of the journal allows one to tolerate some peculiar "findings" - can London's IQ really be lower than Warsaw's? - that have perhaps slipped through the refereeing net in these early days. And the harmless indulgence of the book reviews, in which an imperious view of the world as seen from Denmark Hill is offered as entertainment to some readers and as a caution to others.

Chris Brand is a Lecturer in the Department of Psychology at the University of Edinburgh.

\section{Butterworths}

Publishers of books and journals in law. science and technology. medicine and the social sciences announce the following new journals for $1981 / 82$

Applied Geography

Communist Affairs

Crop Protection

Electoral Studies

Information Technology

International Review of Law and Economics

International Reviews in Physical Chemistry

Journal of International Money and Finance

\section{Monumentum}

Museum Management and Curatorship

\section{Political Geography Quarterly}

\section{Review of International} Studies

(formerly British Journal of International Studies)

\section{Social Science Information Studies}

Textile History

Free specimen copies available on publication. Use this advertisement to tick titles of interest. Or write in for further subscription details and editorial information. 